\title{
Acoustic Simulation and Experimental Studies of Theatres and Concert Halls
}

\author{
T. KAMISIŃSKI \\ Department of Mechanics and Vibroacoustics, AGH University of Science and Technology \\ al. Mickiewicza 30, 30-095 Kraków, Poland
}

Paper presents a numerical simulation of the acoustics of selected concert halls performed using CATT-acoustic software, and the results of acoustic measurements performed in these spaces.

PACS numbers: 43.55.Ka, 43.55.Mc, 43.55.Br

\section{Introduction}

A laboratory study of elements of the interior décor and acoustic issues of the design/implementation process associated with modernisation of the hall interiors is also presented. For each of these halls the results of acoustic simulation helped contribute significantly to the improvement of the interior acoustic characteristics.

\section{Basic theatre hall configurations}

For more than 2500 years, the historical development of the theatre interior has been marked by the close functional relationship of these structures with their users needs. Natural acoustics has always been a characteristic feature of these buildings. It is still important today, when most halls are equipped with loudspeaker systems - often computer controlled. Figure 1 shows the floor plans for three halls, illustrating successive development stages of the theatre building architecture.

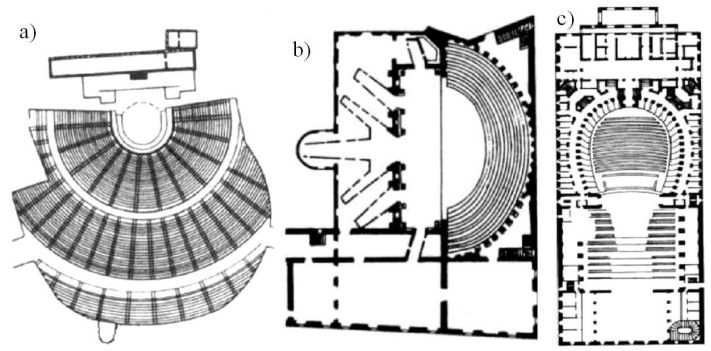

Fig. 1. Plans of theatre buildings: (a) Dionysus Theatre in Athens (452-330 B.C.), (b) Teatro Olimpico in Vicenza (1585), arch.: A. Palladio, (c) La Scala theatre in Milan (1779) arch.: Piermarini [1].

In terms of plan geometry, existing halls currently used can be classified into three groups: those based on a rectangular plan, horseshoe-shaped plan and fan-shaped plan. The resulting geometric features are directly related to their acoustic properties.
The main acoustic parameter of enclosed spaces is the reverberation time. For halls based on rectangular and fan-shaped plans, the reverberation time found theoretically is consistent with the acoustic measurements, whereas for halls based on horseshoe plan the measurement results are lower than those determined theoretically. This is especially the case of opera houses with auditorium capacities below 1000 seats, which are the most numerous.

Halls with a rectangular plan have side walls that ensure short first reflection times, but the large parallel surfaces often result in acoustic defects, such as flutter echoes and standing waves.

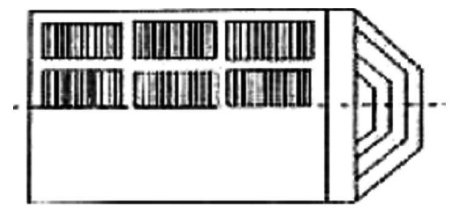

Halls with a fan-shaped plan make it possible to accommodate a large audience while providing good visibility and acoustics. The shape of the hall prevents the formation of flutter echo by side walls, though the sound reflected from the rear wall can reach the front of the auditorium with a significant delay. This can be prevented by covering the rear wall with a sound diffusing or absorbing structure.

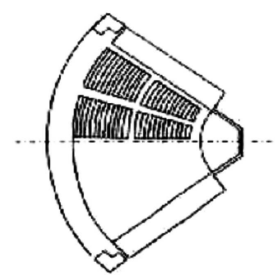

Halls with a horseshoe plan ensure good visibility, a sense of proximity to the sound source and mutual eye contact between the spectators. A large number of boxes and rich interior décor contribute to sound dispersion, which conceals possible acoustic defects and ensures the 
proper ratio of direct to reverberated sound. The large number of listeners and the presence of boxes can result in excessive attenuation of the hall, thus preventing the recommended reverberation time from being attained.

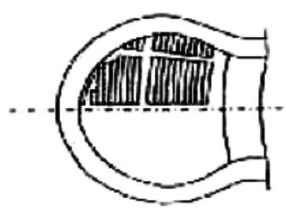

\section{The hall with a rectangular plan}

An example of such an interior is the Krakow Philharmonic Concert Hall (architect: Józef Pokutyński, 1931). This is the largest concert hall in Krakow, intended for symphonic and organ concerts. In 2005 the hall was renovated, which included replacement of the floor and seats, and redecoration of the interior (architect: Krystyna Styrna-Bartkowicz, acoustician: T. Kamisiński). With regard to the acoustics, special focus was paid to the selection of seats, which have a fundamental effect on the hall acoustics. Also, the effect of floor and paints was under control.

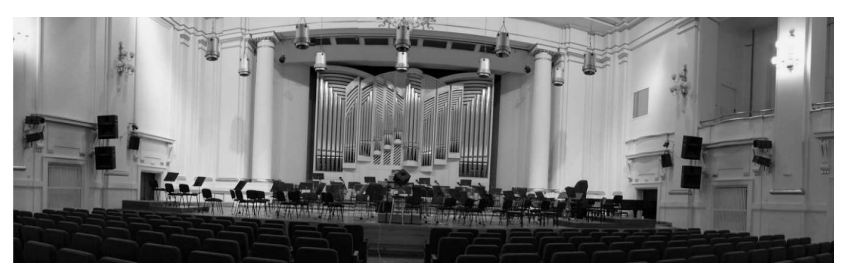

Fig. 2. View of the Kraków Philharmonic Concert Hall.

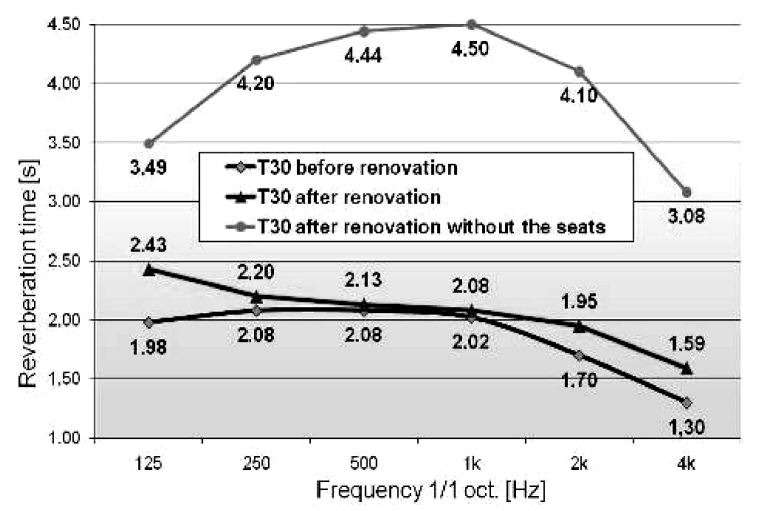

Fig. 3. Reverberation time of the hall without the audience - measured before and after renovation (with and without the seats).

Acoustic studies were performed on the seats that had been used so far and those to be installed. Based on the results of the study and the computer simulation of the

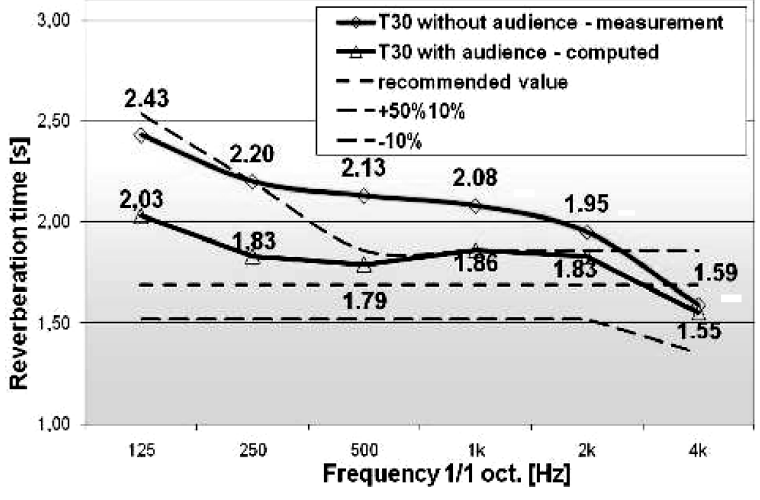

Fig. 4. Reverberation time of the hall after renovation without and with the audience.

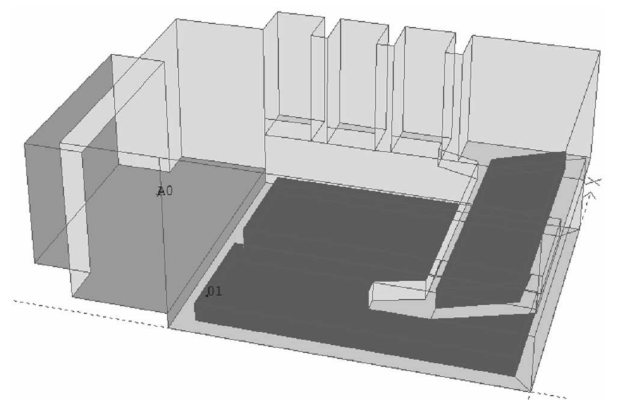

Fig. 5. A view of the hall according to the model developed using CATT-acoustic v.8g software.

hall, changes in the seat construction were recommended, aimed at reducing their acoustic absorption.

The application of the results of the studies and design work resulted in a more uniform characteristics of the hall reverberation time as a function of frequency in a range above $1 \mathrm{kHz}$, and a decrease in the values below $500 \mathrm{~Hz}$. This resulted in an improvement in the subjective evaluation of the sound warmth and clarity. In this case a relatively simple analysis of reverberation time characteristics and sound absorption coefficients of the seats made it possible to formulate recommendations.

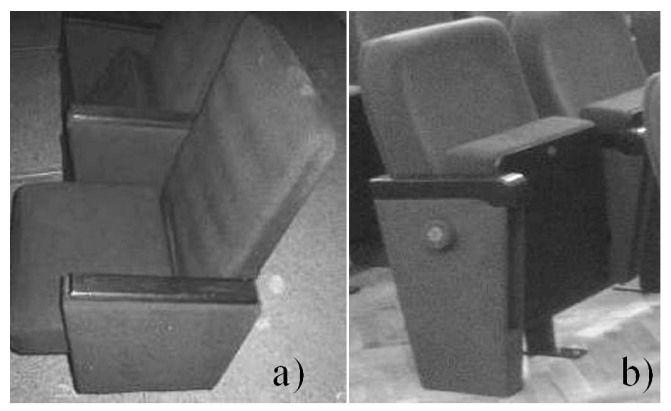

Fig. 6. View of the seats used in the Kraków Philharmonic Concert Hall (a) old seats (b) new seats. 


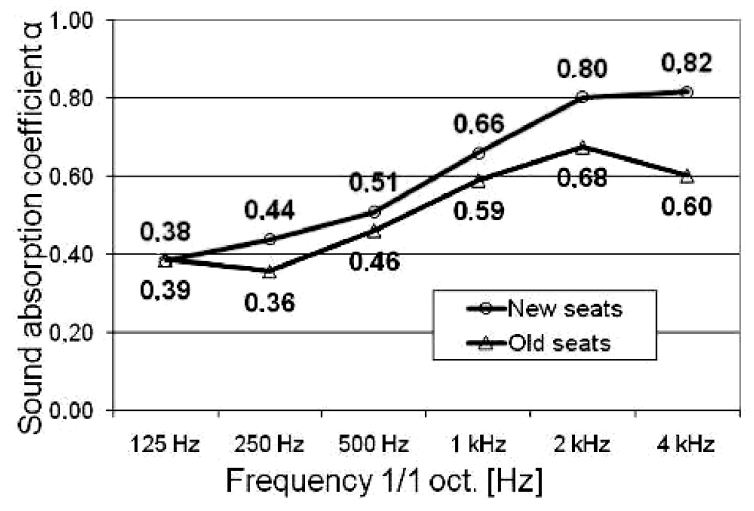

Fig. 7. Comparison of sound absorption coefficients of old and new seats [2].

After the renovation, the hall received favourable opinions from musicians and music lovers. The values recommended in the literature by L. Conturie, J.P. Maxfield and M. Rettinger, which are based on the hall function and volume, agree with the real situation (Figs. 2-7).

\section{The hall with a fan-shaped plan}

An example of a hall with a fan-shaped plan is the Rzeszów Philharmonic Concert Hall (architect: Tadeusz Majewski, acoustician: Witold Straszewicz, 1974). The hall is intended for symphonic concerts and enjoys a good reputation among musicians. In 2008 the hall was renovated, which included replacement of the wood wall and ceiling facing, as well as the replacement of floor and seats (architect: Marek Kozień, Magdalena Kozień, acoustician: T. Kamisiński). The purpose of the renovation was to meet fire safety regulations while maintaining the existing décor of the interior, and without having an adverse effect on the acoustics.

Krakow Philharmonic Concert Hall data: Concert hall volume: $V=7590 \mathrm{~m}^{3}$, Number of seats before and after renovation: 826/729. For symphonic concerts: acc. to L. Conturie: $T=0.09 V^{1 / 3}=1.77 \mathrm{~s}$, acc. to J.P. Maxfield: $T=0.38 V^{1 / 6}=1.68 \mathrm{~s}$, acc. to M. Rettinger: $T=0.30 \log V+0.46=1.62 \mathrm{~s}$, recommended value: $T_{\text {av. }(0.5-1 \mathrm{kHz})}=1.69 \mathrm{~s}$, measured value, equal to that simulated: $T_{\mathrm{av} .(0.5-1 \mathrm{kHz})}=1.83 \mathrm{~s}$, (Formulae given after: $[3,4]$.

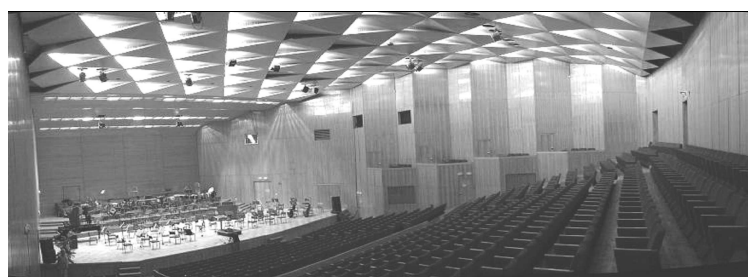

Fig. 8. View of the Rzeszów Philharmonic Concert Hall.

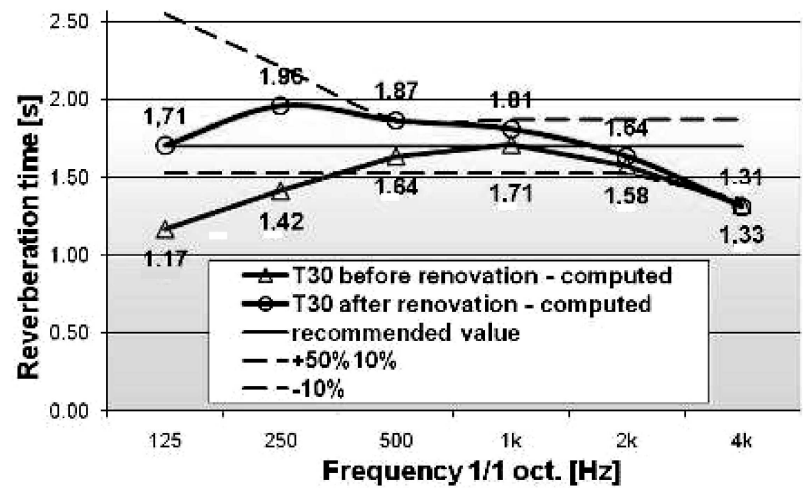

Fig. 9. Reverberation time of the hall before and after renovation — with the audience and orchestra, numerical simulation.

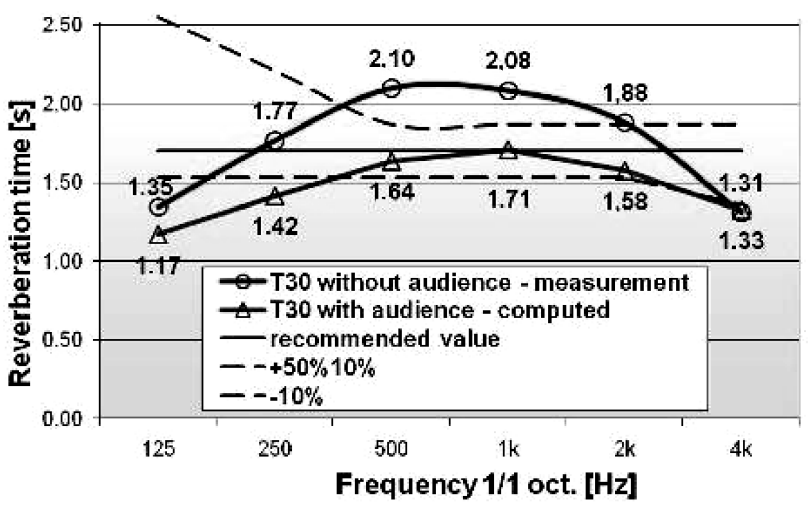

Fig. 10. Assessment of the reverberation time according to numerical simulation for the hall with the audience.

Rzeszów Philharmonic Concert Hall Data: Concert hall volume: $7050 \mathrm{~m}^{3}+150 \mathrm{~m}^{3}$ orchestra pit, Number of seats in the auditorium: $757+43$. For symphonic concerts: acc. to L. Conturie: $T=0.09 \mathrm{~V}^{1 / 3}=1.73 \mathrm{~s}$, acc. to J.P. Maxfield: $T=0.38 \mathrm{~V}^{1 / 6}=1.66 \mathrm{~s}$, acc. to M. Rettinger: $T=0.30 \log \mathrm{V}+0.46=1.61 \mathrm{~s}$, recommended value: $T_{\text {av. }(0.5-1 \mathrm{kHz})}=1.66 \mathrm{~s}$, measured and simulated values: $T_{\mathrm{av} .(0.5-1 \mathrm{kHz})}=1.68 \mathrm{~s}$ (Formulae given after: [3, 4].)

Before the renovation of the concert hall, acoustic measurements and computer simulations were performed and the materials used for renovation were consulted with the architect. As a result, a new wall and seat materials were selected. Analysis of the reverberation time as a function of frequency indicated the need to increase the reverberation time in a frequency range below $500 \mathrm{~Hz}$. This conclusion is consistent with the opinions of the hall users, who praised the superb acoustics of the hall, but also admitted that the sound warmth effect had been unsatisfactory. These conclusions are consistent with the recommendations formulated by L. Conturie, J.P. Maxfield and M. Rettinger (Fig. 8-12). 


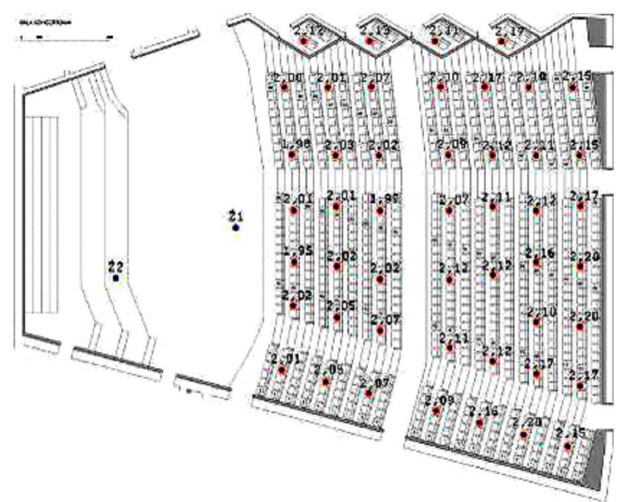

Fig. 11. A plan of the hall with marked measurement points.

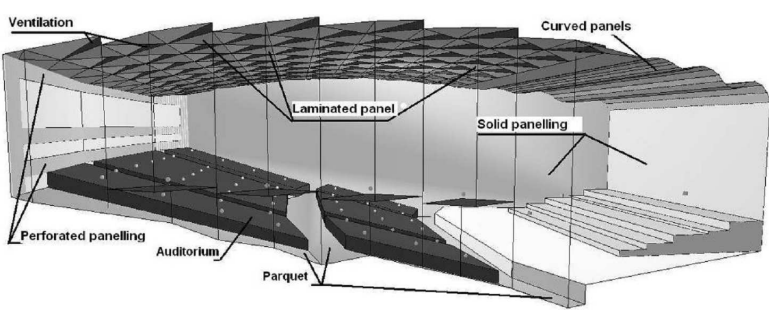

Fig. 12. View of the hall according to the model developed with CATT-acoustic v. $8 \mathrm{~g}$ software.

\section{The hall with a horseshoe-shaped plan}

An example of a hall with a horseshoe-shaped plan is the Salomea Kruszelnicka Academic Opera and Ballet Theatre in Lviv, also called the Lviv Opera House. The edifice was designed by Zygmunt Gorgolewski (1900), one of the most outstanding architects of the time. The auditorium has a volume of 4549 cubic meters and can accommodate 998 people. In 2008 the hall was renovated, which included the replacement of the floor, elements of the upholstery, as well as the redecoration of the interior. To maintain the acoustic properties, acoustic measurements of the interior, numerical simulation and laboratory tests on selected interior materials (planks, carpets, valances) were performed. The design for the best floor installation, ensuring the best sound absorption characteristics in the range of low frequencies, was indicated [5].

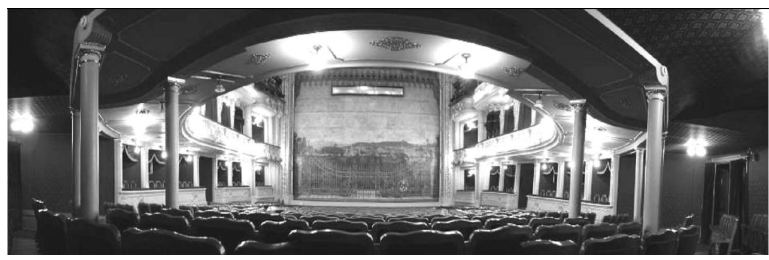

Fig. 13. View of the Lviv Opera House after renovation.
The Lviv Opera concert hall data: Concert hall volume: $4374 \mathrm{~m}^{3}+175 \mathrm{~m}^{3}$ orchestra pit. Number of seats: 998. For opera and theatre halls: acc. to L. Conturie: $T=0.075 V^{1 / 3}=1.23 \mathrm{~s}$ acc. to M. Rettinger: $T=0.25 \log V+0.39=1.30 \mathrm{~s}$ Recommended value: $T_{\text {av. }(0.5-1 \mathrm{kHz})}=1.26 \mathrm{~s}$ Measured and simulated value: $T_{\text {av. }(0.5-1 \mathrm{kHz})}=1.09 \mathrm{~s}$ (Formulae given after: $\left.[3,4].\right)$

\section{Correction of the criteria of acoustic evaluation of horseshoe-shaped halls}

Based on the literature relating to concert hall acoustics, the geometric, functional and acoustic parameters of the Opera House in Lviv were analyzed. The texts in Fig. 14 specifies the relevant data and algorithms resulting from the author's own studies and those taken from the literature. The recommendations formulated by L. Conturie, J.P. Maxfield and M. Rettinger differ from the measurement data (Fig. 14). Table summarises

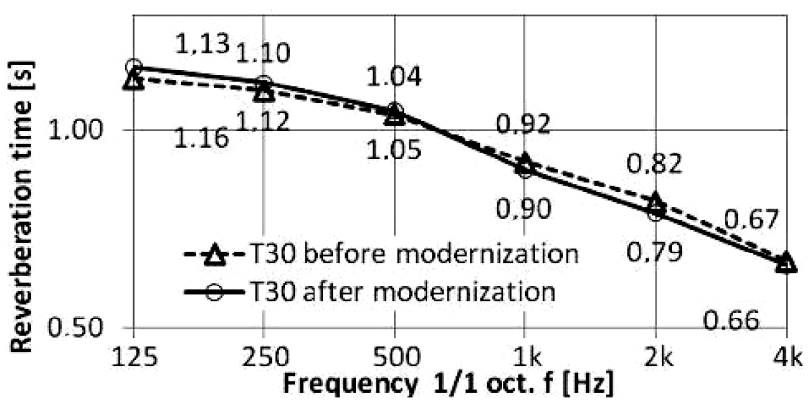

Fig. 14. Reverberation time of the hall before and after renovation according to the numerical simulation of the hall with the audience.

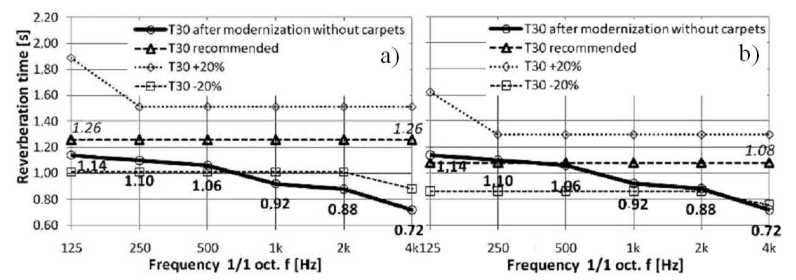

Fig. 15. Assessed reverberation time T30 of the Lviv Opera House after modernisation - numerical simulation of the hall with the audience (a) according to general recommendations in the literature, (b) according to the author's recommendation.

the values used as a basis to determine the desirable average time range for several selected horseshoe-shaped halls with renowned acoustics. Whereas the algorithms provide correct values of the reverberation times of halls based on the rectangular and fan-shaped plans (Figs. 3-5, 9-10), the measurements for halls based on a horseshoe-shaped plan gave lower values. On the basis of the approximation of the set of data, the author attempted to 
formulate an algorithm that would better define the recommended reverberation time $T_{\mathrm{av} .}(0.5-1 \mathrm{kHz}$ for opera and theatre halls with the auditorium based on the horseshoe-shaped plan.

The formula $T_{\mathrm{av} .(0.5-1 \mathrm{kHz})}=0.11 \mathrm{~V} / \mathrm{N}+0.6(\mathrm{~V}, \mathrm{~N}$ : hall volume in $\mathrm{m}^{3}$ and the number of seats in the auditorium, respectively) seems to give a better representation of such halls than the formulae given in the literature.
In Fig. 15b, ranges of the reverberation time are marked according to the criteria formulated by the author for opera halls and auditoriums based on the horseshoe-shaped plan. It can be noted that such halls are characterised by lower reverberation times due to the complex auditorium arrangement involving balconies and boxes. Also, rich ornamentation and upholstery significantly affect the sound absorption of the interior.

TABLE

Parameters and criteria of assessment of the reverberation time in opera and theatre halls.

\begin{tabular}{|c|c|c|c|c|c|c|c|}
\hline \multicolumn{8}{|c|}{ Theatre halls based on the horseshoe-shaped plan } \\
\hline Parameter & $\begin{array}{l}\text { Lviv } \\
\text { Opera } \\
\text { House }\end{array}$ & $\begin{array}{c}\text { Paris } \\
\text { Opera } \\
\text { Garnier }\end{array}$ & $\begin{array}{c}\text { Vienna } \\
\text { Staatsoper }\end{array}$ & $\begin{array}{c}\text { Milan } \\
\text { La Scala }\end{array}$ & $\begin{array}{c}\text { London } \\
\text { Royal } \\
\text { Opera } \\
\text { House }\end{array}$ & $\begin{array}{l}\text { Values recommended } \\
\text { for opera halls (according } \\
\text { to the literature) }\end{array}$ & Source \\
\hline Number of seats & 1050 & 2130 & 1709 & 2289 & 2120 & & \\
\hline Volume $\left[\mathrm{m}^{3}\right]$ & 4549 & 10000 & 10665 & 11252 & 12250 & $\max 15000$ & Neufert [1] \\
\hline \multirow{2}{*}{$\begin{array}{c}\text { Volume per person } \\
{\left[\mathrm{m}^{3} / \text { person }\right]}\end{array}$} & \multirow{2}{*}{4.3} & \multirow{2}{*}{4.7} & \multirow{2}{*}{6.2} & \multirow{2}{*}{4.9} & \multirow{2}{*}{5.8} & $4-6$ & Tempelton \\
\hline & & & & & & $5-8$ & Neufert [1] \\
\hline \multirow{3}{*}{$\begin{array}{c}T_{\text {av. }}(0.5-1 \mathrm{kHz})[\mathrm{s}] \\
\text { with the audience }\end{array}$} & \multirow{3}{*}{0.98} & \multirow{3}{*}{1.15} & \multirow{3}{*}{1.30} & \multirow{3}{*}{1.20} & \multirow{3}{*}{1.10} & 1.3 & Rettinger \\
\hline & & & & & & $1.3-1.6$ & Meyer and Neuman \\
\hline & & & & & & $1.4-1.7$ & Bruckmayer \\
\hline \multirow{3}{*}{$\begin{array}{c}\text { Recommended } \\
T_{\text {av. }}[\mathrm{s}]\end{array}$} & 1.24 & 1.62 & 1.65 & 1.68 & 1.73 & $T=0.075(V)^{1 / 3}$ & Conturie \\
\hline & 1.30 & 1.39 & 1.40 & 1.40 & 1.41 & $T=0.25 \log V+0.39$ & Rettinger \\
\hline & 1.08 & 1.12 & 1.29 & 1.14 & 1.24 & $T=0.11 V / N+0.6$ & Author \\
\hline
\end{tabular}

\section{Summary and conclusions}

The introductory part of the paper summarises the main features of the three basic configurations of theatre and music halls. However, a deeper analysis of the acoustic properties of these interiors indicates a number of additional features significant for the architect and acoustician: in halls based on a rectangular plan, a modification of the rear wall is essential; in fan-shaped halls, reflective structures under the ceiling are significant, which compensate for the lack of side reflections, and also structures on the rear wall to prevent undesirable reflections toward the front of the hall, whereas in horseshoe-shaped halls all interior elements adding to acoustic absorption, such as carpets and abundant upholstery, should be reduced. The deviation from the measurement data motivated the author to attempt to formulate an algorithm defining the recommended reverberation time for opera and theatre halls with a horseshoe-shaped audience. This algorithm is based on the volume per person index $(V / N)$. Analysis of this issue is given in Table.

\section{References}

[1] E. Neufert, Handbook of Building Design, Arkady, Warszawa 2005.

[2] T. Kamisiński, Report on The Measurements of Sound Absorption of Audience Chairs at The Karol Szymanowski Philharmonic in Cracow, AGH, 2005.

[3] L. Beranek, Concert and Opera Halls: How They Sound, Acoustical Society of America, New York 2006.

[4] A. Kulowski, Room Acoustics, Wydawnictwo Politechniki Gdańskiej, Gdańsk 2007.

[5] T. Kamisiński, R. Kinasz, J. Rubacha, A. Pilch, J. Urbanek, Acoustics of The Audience Room at The Lviv Theatre Of Opera And Ballet, WibroTech, Kraków 2008, p. 99. 